\title{
THE
}

\section{US GODAE: Global Ocean Prediction with the HYbrid Coordinate Ocean Model (HYCOM)}

Eric P. Chassignet

Harley E. Hurlburt

E. Joseph Metzger

Ole Martin Smedstad

James A. Cummings

See next page for additional authors

Follow this and additional works at: https://digitalcommons.uri.edu/gsofacpubs

Terms of Use

All rights reserved under copyright.

\section{Citation/Publisher Attribution}

Chassignet, E.P., H.E. Hurlburt, E.J. Metzger, O.M. Smedstad, J.A. Cummings, G.R. Halliwell, R. Bleck, R. Baraille, A.J. Wallcraft, C. Lozano, H.L. Tolman, A. Srinivasan, S. Hankin, P. Cornillon, R. Weisberg, A. Barth, R. He, F. Werner, and J. Wilkin. 2009. US GODAE: Global ocean prediction with the HYbrid Coordinate Ocean Model (HYCOM). Oceanography 22(2):64-75, https://doi.org/10.5670/oceanog.2009.39.

Available at: https://doi.org/10.5670/oceanog.2009.39

This Article is brought to you for free and open access by the Graduate School of Oceanography at DigitalCommons@URI. It has been accepted for inclusion in Graduate School of Oceanography Faculty Publications by an authorized administrator of DigitalCommons@URI. For more information, please contact digitalcommons-group@uri.edu. 


\section{Authors}

Eric P. Chassignet, Harley E. Hurlburt, E. Joseph Metzger, Ole Martin Smedstad, James A. Cummings, George R. Halliwell, Rainer Bleck, Remy Baraille, Alan J. Wallcraft, Carlos Lozano, Hendrik L. Tolman, Ashwanth Srinivasan, Steven Hankin, Peter C. Cornillon, Robert Weisberg, Alexander Barth, Ruoying He, Francisco Werner, and John Wilkin 


\section{Oceanography}

CITATION

Chassignet, E.P., H.E. Hurlburt, E.J. Metzger, O.M. Smedstad, J.A. Cummings, G.R. Halliwell,

R. Bleck, R. Baraille, A.J. Wallcraft, C. Lozano, H.L. Tolman, A. Srinivasan, S. Hankin, P. Cornillon,

R. Weisberg, A. Barth, R. He, F. Werner, and J. Wilkin. 2009. US GODAE: Global ocean

prediction with the HYbrid Coordinate Ocean Model (HYCOM). Oceanography 22(2):64-75,

doi:10.5670/oceanog.2009.39.

\section{COPYRIGHT}

This article has been published in Oceanography, Volume 22, Number 2, a quarterly journal of The Oceanography Society. Copyright 2009 by The Oceanography Society. All rights reserved.

USAGE

Permission is granted to copy this article for use in teaching and research. Republication, systematic reproduction, or collective redistribution of any portion of this article by photocopy machine, reposting, or other means is permitted only with the approval of The Oceanography Society. Send all correspondence to: info@tos.org or The Oceanography Society, PO Box 1931, Rockville, MD 20849-1931, USA. 


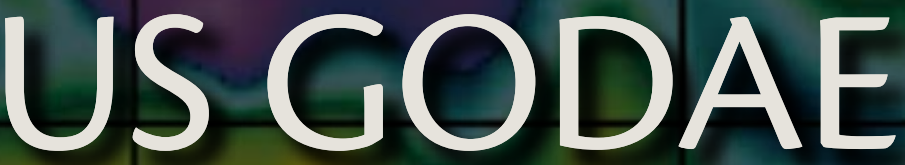

\section{Global Ocean Prediction with the} HYbrid Coordinate Ocean Model (HYCOM)

BY ERIC P. CHASSIGNET, HARLEY E. HURLBURT, E. JOSEPH METZGER, OLE MARTIN SMEDSTAD, JAMES A. CUMMINGS, GEORGE R. HALLIWELL, RAINER BLECK, REMY BARAILLE, ALAN J. WALLCRAFT, CARLOS LOZANO, HENDRIK L. TOLMAN, ASHWANTH SRINIVASAN, STEVE HANKIN, PETER CORNILLON, ROBERT WEISBERG, ALEXANDER BARTH, RUOYING HE, 
ABSTRACT. During the past five to ten years, a broad partnership of institutions under NOPP sponsorship has collaborated in developing and demonstrating the performance and application of eddy-resolving, real-time global- and basin-scale ocean prediction systems using the HYbrid Coordinate Ocean Model (HYCOM). The partnership represents a broad spectrum of the oceanographic community, bringing together academia, federal agencies, and industry/commercial entities, and spanning modeling, data assimilation, data management and serving, observational capabilities, and application of HYCOM prediction system outputs. In addition to providing real-time, eddy-resolving global- and basin-scale ocean prediction systems for the US Navy and NOAA, this project also offered an outstanding opportunity for NOAA-Navy collaboration and cooperation, ranging from research to the operational level. This paper provides an overview of the global HYCOM ocean prediction system and highlights some of its achievements. An important outcome of this effort is the capability of the global system to provide boundary conditions to even higherresolution regional and coastal models.

\section{INTRODUCTION}

A broad partnership of institutions has collaborated over the past five to ten years to develop and demonstrate the performance and application of eddyresolving, real-time global- and basinscale ocean prediction systems using the HYbrid Coordinate Ocean Model (HYCOM). These systems are in the process of being transitioned to operational use by the US Navy at the Naval Oceanographic Office (NAVOCEANO), Stennis Space Center, Mississippi, and by the National Oceanic and Atmospheric Administration (NOAA) at the National Centers for Environmental Prediction (NCEP), Washington, DC. The systems run efficiently on a variety of massively parallel computers and include sophisticated, but relatively inexpensive, data assimilation techniques for satellite altimeter sea surface height (SSH) and sea surface temperature (SST) as well as in situ temperature, salinity, and float displacement. The partnership represents a broad spectrum of the oceanographic community, bringing together academia, federal agencies, and industry/ commercial entities in activities that span modeling, data assimilation, data management and serving, observational capabilities, and application of HYCOM prediction system outputs. All participating institutions were committed and the collaborative partnership provided an opportunity to leverage and accelerate the efforts of existing and planned projects, consequently producing a highquality product that should collectively serve a wider range of users than would the individual projects.

The collaboration was initiated in the late 1990s by ocean modelers at the Naval Research Laboratory, Stennis, Mississippi, who approached colleagues at the University of Miami’s Rosenstiel School of Marine and Atmospheric Science regarding an extension of the range of applicability of the US Navy operational ocean prediction system to coastal regions (e.g., the US Navy systems at the time were seriously limited in shallow water and in handling the transition from deep to shallow water). HYCOM (Bleck,
2002) was therefore designed to extend the range of existing operational Ocean General Circulation Models (OGCMs). The freedom to adjust the vertical spacing of the generalized (or hybrid) coordinate layers in HYCOM simplifies the numerical implementation of several processes and allows for a smooth transition from the deep ocean to coastal regimes. HYCOM retains many of the characteristics of its predecessor, the Miami Isopycnic Coordinate Ocean Model (Bleck et al., 1992; Bleck and Chassignet, 1994), while allowing coordinates to locally deviate from isopycnals wherever the latter may fold, outcrop, or generally provide inadequate vertical resolution. The collaboration led to the development of a consortium for hybrid-coordinate data assimilative ocean modeling supported by NOPP to make HYCOM a state-of-the-art community ocean model with data assimilation capability that could: (1) be used in a wide range of ocean-related research, (2) become the next-generation eddy-resolving global ocean prediction system, and (3) be coupled to a variety of other models, including littoral, atmospheric, ice, and biochemical models. One outcome of this collaboration was the establishment of a near-real-time North Atlantic prediction system based on HYCOM.

In 2003, NOAA NCEP joined forces with the HYCOM consortium in responding to a NOPP Broad Agency Announcement aimed at "implementing the initial, preoperational US contribution(s) to the Global Ocean Data Assimilation Experiment (GODAE)." These efforts were intended to be pilot projects under Ocean.US, the National Office for Integrated and Sustained Ocean Observations, and to 
eventually lead to sustained operational efforts supported by US agencies such as NOAA and the Navy. The HYCOM consortium therefore became one of the US components of GODAE, a coordinated international system of observations, communications, modeling, and assimilation that delivers regular, comprehensive information on the state of the ocean (see Chassignet and Verron, 2006, for a review). Navy and NOAA applications, such as maritime safety, fisheries, the offshore industry, and management of shelf/coastal areas, are among the expected beneficiaries of the HYCOM ocean prediction systems (http://www.hycom.org). More specifically, the precise knowledge and prediction of ocean mesoscale features helps the Navy, NOAA, Coast Guard, industry, and fisheries with endeavors such as ship and submarine routing, search and rescue, oil spill drift prediction, open-ocean ecosystem monitoring,

Eric P. Chassignet (echassignet@coaps.fsu.edu) is Professor and Director, Center for Ocean-Atmospheric Prediction Studies, Florida State University, Tallahassee, FL, USA. Harley E. Hurlburt is Senior Scientist for Ocean Modeling and Prediction, Naval Research Laboratory (NRL), Stennis Space Center, MS, USA. E. Joseph Metzger is Meteorologist, Ocean Dynamics and Prediction Branch, NRL, Stennis Space Center, MS, USA.

Ole Martin Smedstad is Principal Scientist, QinetiQ North America-Technology Solutions Group, Stennis Space Center, MS, USA. James A. Cummings is Oceanographer, Ocean Dynamics and Prediction Branch, NRL, Stennis Space Center, MS, USA. George R. Halliwell is Research Scientist, Atlantic Oceanographic and Meteorological Laboratory, National Oceanic and Atmospheric Administration (NOAA), Miami, FL, USA. Rainer Bleck is Research Scientist, Goddard Institute for Space Studies, National Aeronautics and Space Administration, New York, NY, USA, and Earth Systems Research Laboratory, NOAA, Boulder, CO, USA. Remy Baraille is Research Scientist, Service Hydrographique et Océanographique de la Marine, Toulouse, France. Alan J. Wallcraft is Computer Scientist, Ocean Dynamics and Prediction Branch, NRL, Stennis Space Center, MS, USA. Carlos Lozano is Physical Scientist, Environmental Modeling Center, National Centers for Environmental Prediction, NOAA, Camp Springs, MD, USA. Hendrik L. Tolman is Branch Chief, Environmental Modeling Center, National Centers for Environmental Prediction, Marine Modeling and Analysis Branch, NOAA, Camp Springs, MD, USA. Ashwanth Srinivasan is Research Assistant Professor, Division of Meteorology and Oceanography, Rosenstiel School of Marine and Atmospheric Science, University of Miami, Miami, FL, USA. Steve Hankin is Research Scientist, Pacific Marine Environmental Laboratory, NOAA, Seattle, WA, USA. Peter Cornillon is Professor, Graduate School of Oceanography, University of Rhode Island, Narragansett, RI, USA. Robert Weisberg is Professor, College of Marine Science, University of South Florida, St. Petersburg, FL, USA. Alexander Barth is Research Scientist, GeoHydrodynamics and Environment Research, University of Liège, Liège, Belgium. Ruoying He is Associate Professor, Department of Marine, Earth and Atmospheric Sciences, North Carolina State University, Raleigh, NC, USA. Francisco Werner is Director and Professor, Institute of Marine and Coastal Sciences, Rutgers University, New Brunswick, NJ, USA. John Wilkin is Associate Professor, Institute of Marine and Coastal Sciences, Rutgers University, New Brunswick, NJ, USA.

fisheries management, and short-range coupled atmosphere-ocean, coastal, and nearshore environmental forecasting. In addition to operational eddyresolving global- and basin-scale ocean prediction systems for the US Navy and NOAA, respectively, this project offered an outstanding opportunity for NOAA-Navy collaboration and cooperation ranging from research to the operational level.

\section{BACKGROUND}

Over the past several decades, numerical modeling studies have demonstrated progress in both model architecture and the availability of computational resources to the scientific community. Perhaps the most noticeable aspect of these advances has been the evolution from simulations on coarse-resolution horizontal/vertical grids outlining basins of simplified geometry and bathymetry and forced by idealized stresses, to fineresolution simulations incorporating realistic coastal definition and bottom topography and forced by observational data on relatively short time scales (Hurlburt and Hogan, 2000; Smith et al., 2000; Chassignet and Garraffo, 2001; Maltrud and McClean, 2005; Hurlburt et al., 2008). The choice of the vertical coordinate system, however, remains one of the most important aspects of an ocean model's design. In practice, the representation and parameterization of processes not resolved by the model grid are often directly linked to the vertical coordinate choice (Griffies et al., 2000). Oceanic general circulation models traditionally represent the vertical in a series of discrete intervals in either a depth, density, or terrain-following unit. Because none of the three main vertical 
coordinates (depth, density, and terrainfollowing) provide universal optimality, it is natural to envision a hybrid approach that combines the best features of each vertical coordinate. Isopycnic (potential density-tracking) layers work best for modeling the deep stratified ocean; levels at constant fixed depth or pressure are best for providing high vertical resolution near the surface within the mixed layer; and terrain-following levels are often the best choice for modeling shallow coastal regions. In HYCOM, the optimal vertical coordinate distribution of the three vertical coordinate types is chosen at every time step and in every grid column individually. The default configuration of HYCOM is isopycnic in the open stratified ocean, but it makes a dynamically and geometrically smooth transition to terrain-following coordinates in shallow coastal regions and to fixed pressure-level coordinates in the surface mixed layer and/or unstratified open seas. In doing so, the model takes advantage of the different coordinate types in optimally simulating coastal and open-ocean circulation features (Chassignet et al., 2003, 2006,2007 ). A user-chosen option allows specification of the vertical coordinate separation that controls the transition among the three coordinate systems. The assignment of additional coordinate surfaces to the oceanic mixed layer also allows the straightforward implementation of multiple vertical mixing turbulence closure schemes (Halliwell, 2004). The choice of the vertical mixing parameterization is also of importance in areas of strong entrainment, such as overflows.

Data assimilation is essential for ocean prediction because: (a) many ocean phenomena are due to nonlinear processes (i.e., flow instabilities) and thus are not a deterministic response to atmospheric forcing, (b) errors exist in the atmospheric forcing, and (c) ocean models are imperfect, including limitations in numerical algorithms and in resolution. Most of the information about the ocean surface's space-time variability is obtained remotely from instruments aboard satellites (SSH and SST), but these observations are insufficient for specifying the subsurface variability. Vertical profiles from expendable bathythermographs (XBT), conductivitytemperature-depth (CTD) profilers, and profiling floats (e.g., Argo, which measures temperature and salinity in the upper $2000 \mathrm{~m}$ of the ocean) provide another substantial source of data. Even together, these data sets are insufficient to determine the ocean's state completely, so it is necessary to exploit prior statistical knowledge based on past observations as well as our present understanding of ocean dynamics. By combining all of these observations through data assimilation into an ocean model, it is possible, in principle, to produce a dynamically consistent depiction of the ocean. However, in order to have any predictive capabilities, it is extremely important that the freely evolving ocean model (i.e., non-data-assimilative model) is skilled in representing ocean features of interest.

To properly assimilate the SSH anomalies determined from satellite altimeter data, the oceanic mean SSH over the altimeter observation period must be provided. In this mean, it is essential that the mean current systems and associated $\mathrm{SSH}$ fronts be accurately represented in terms of position, amplitude, and sharpness. Unfortunately, Earth's geoid is not presently known with sufficient accuracy for this purpose, and coarse hydrographic climatologies $\left(\sim 0.5^{\circ}-1^{\circ}\right.$ horizontal resolution) cannot provide the spatial resolution necessary when assimilating SSH in an eddy-resolving model (horizontal grid spacing of $1 / 10^{\circ}$ or finer). At these scales of interest, it is essential to have the observed means of boundary currents and associated fronts sharply defined (Hurlburt et al., 2008). Figure 1 shows the climatological mean derived on a $0.5^{\circ}$ grid using surface drifters by Maximenko and Niiler (2005) as well as the mean currently used in the Navy global HYCOM prediction system (see following section for details). The HYCOM mean was constructed as follows: a five-year mean SSH field from a non-data-assimilative $1 / 12^{\circ}$ global HYCOM run was compared to available climatologies, and a rubber-sheeting technique (Carnes et al., 1996) was used to modify the model mean in two regions (the Gulf Stream and the Kuroshio) where the western boundary current extensions were not well represented and where an accurate frontal location is crucial for ocean prediction. Rubber sheeting involves a suite of computer programs that operate on SSH fields, overlaying contours from a reference field and moving masses.

\section{THE HYCOM OCEAN PREDICTION SYSTEMS}

Two systems are currently run in real time by the US Navy at NAVOCEANO, Stennis Space Center, Mississippi, and by NOAA at NCEP, Washington, DC (http://www.hycom.org).

The first system is the NOAA Real Time Ocean Forecast System for the Atlantic (RTOFS-Atlantic), which has been running in real time since 2005. 

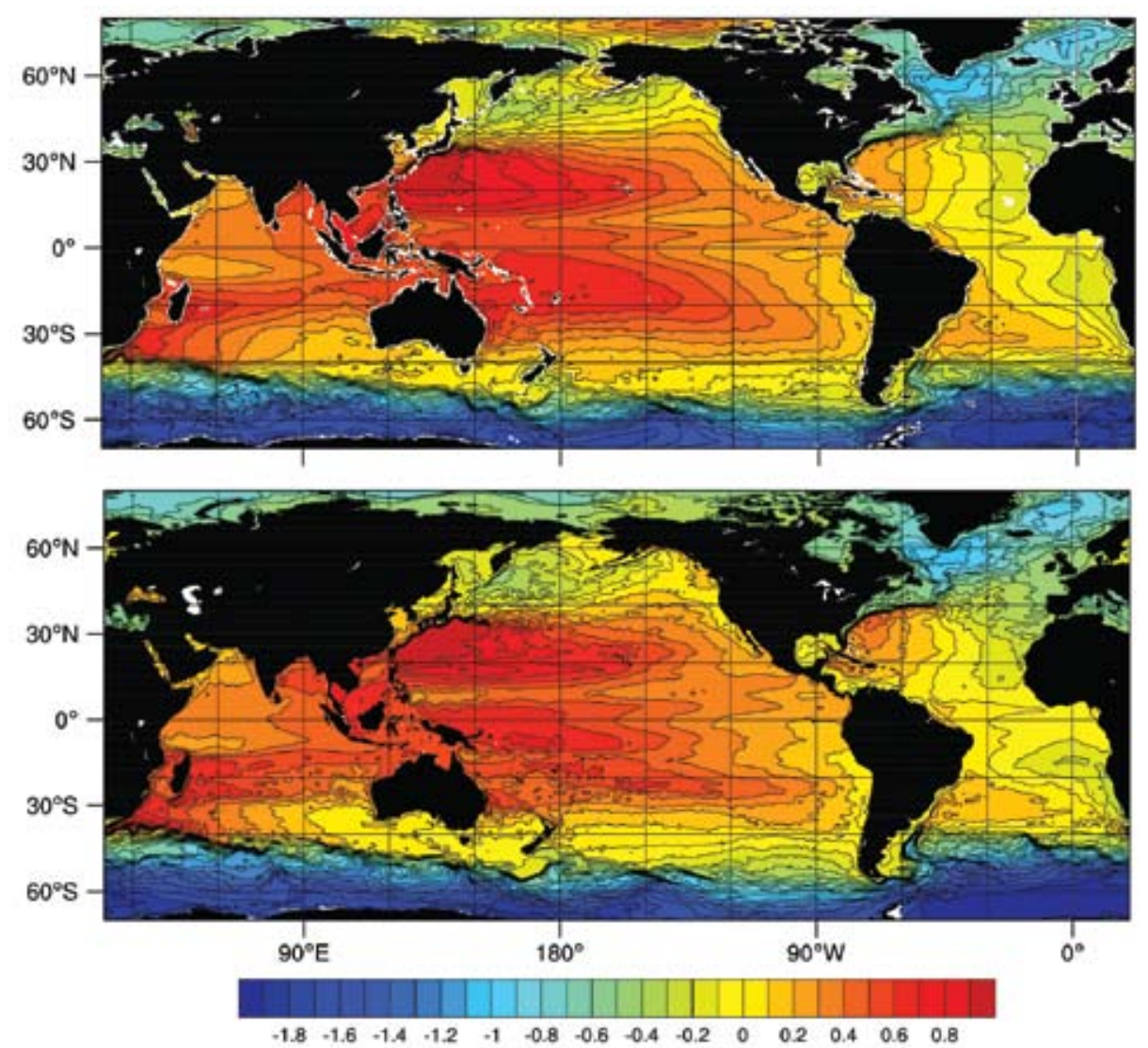

Figure 1. The top panel shows mean sea surface height (in $\mathrm{cm}$ ) derived from surface drifters (Maximenko and Niiler, 2005), and the bottom panel shows the same from a non-dataassimilative HYCOM run corrected in the Gulf Stream and Kuroshio regions using a rubbersheeting technique. The RMS difference between the two fields is $9.2 \mathrm{~cm}$.

The Atlantic domain spans $25^{\circ} \mathrm{S}$ to $76^{\circ} \mathrm{N}$ with a horizontal resolution varying from $4 \mathrm{~km}$ near the US coastline to $20 \mathrm{~km}$ near the African coast. The system is run daily with one-day nowcasts and five-day forecasts. Prior to June 2007, only the SST was assimilated. In June 2007, NOAA implemented the threedimensional variational data assimilation of: (1) SST and SSH (Jason-1, Geosat Follow-On [GFO], and soon Envisat), (2) temperature and salinity profile assimilation (e.g., Argo, CTDs, moorings), and (3) GOES data. Plans are to expand this system globally using the US Navy configuration described in the following paragraph. The NCEP RTOFS-Atlantic model data is distributed in real time through NCEP's operational ftp server (ftp://ftpprd.ncep. noaa.gov) and the NOAA Operational Model Archive and Distribution System (NOMADS; http://nomads6.ncdc.noaa. gov/ncep_data/index.html) server. The latter server is also using Open Project for a Network Data Access Protocol (OPeNDAP) middleware as a data-access method. NCEP's RTOFS-Atlantic model data is also archived at the National Oceanographic Data Center (NODC, http://data.nodc.noaa.gov/ncep/rtofs).

The second system is the global
US Navy nowcast/forecast system using the $1 / 12^{\circ}$ global HYCOM $(6.5-\mathrm{km}$ grid spacing on average, $3.5-\mathrm{km}$ grid spacing at the North Pole, and 32 hybrid layers in the vertical), which has been running in near real time since December 2006 and in real time since February 2007. The current ice model is thermodynamic, but it will soon include more physics as it is upgraded to the Polar Ice Prediction System (PIPS, based on the Los Alamos ice model known as CICE). The model is currently running daily on 379 processors on an IBM Power 5+ at NAVOCEANO using a part of the operational allocation on the machine. The daily run consists of a five-day hindcast and a five-day forecast and takes about 15 wall clock hours. The system assimilates (1) SSH (Envisat, GFO, and Jason-1), (2) SST (all available satellite and in situ sources),

(3) all available in situ temperature and salinity profiles (e.g., Argo, CTDs, moorings), and (4) Special Sensor Microwave/ Imager (SSMI) sea ice concentration. The three-dimensional multivariate optimum interpolation Navy Coupled Ocean Data Assimilation (NCODA) system (Cummings, 2005) is the assimilation technique. The NCODA horizontal correlations are multivariate in geopotential and velocity, thereby permitting adjustments (increments) to the mass field to be correlated with adjustments to the flow field. The velocity adjustments are in geostrophic balance with the geopotential increments, and the geopotential increments are in hydrostatic agreement with the temperature and salinity increments. Either the Cooper and Haines (1996) technique or synthetic temperature and salinity profiles (Fox et al., 2002) can be 


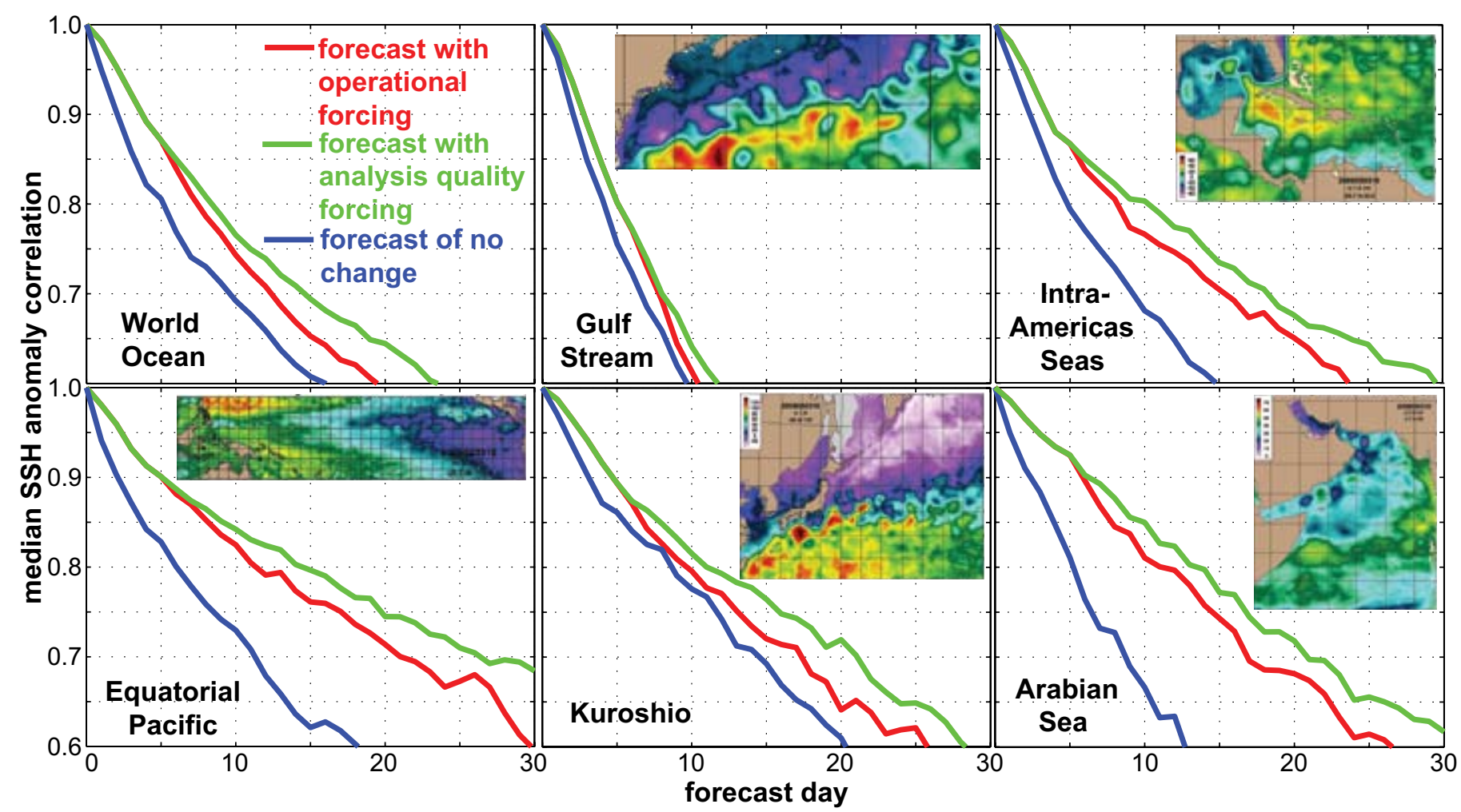

Figure 2. Verification of 30-day ocean forecasts: median SSH anomaly correlation vs. forecast length in comparison with the verifying analysis for the global US Navy HYCOM over the world ocean and five subregions. The red curves verify forecasts using operational atmospheric forcing, which reverts toward climatology after five days. The green curves verify "forecasts" with analysis quality forcing for the duration, and the blue curves verify forecasts of persistence (i.e., no change from the initial state). The plots show median statistics over twenty 30-day HYCOM forecasts initialized during January 2004-December 2005, a period when data from three nadir-beam altimeters, Envisat, GEOSAT Follow-on, and Jason-1, were assimilated. The reader is referred to Hurlburt et al. (2008) and an article scheduled for the September 2009 issue of Oceanography for a more detailed discussion of these results.

used for downward projection of SSH and SST. Figure 2 shows an example of forecast performance.

Validation of the results is underway using independent data with a focus on the large-scale circulation features, $\mathrm{SSH}$ variability, eddy kinetic energy, mixedlayer depth, vertical profiles of temperature and salinity, SST, and coastal sea levels. Figures 3 and 4 show examples for the Gulf Stream region, while Figure 5 documents the performance of HYCOM in representing the mixed-layer depth. HYCOM is also included in the international GODAE comparison of global ocean forecasting systems.

\section{DISTRIBUTION OF \\ GLOBAL HYCOM HINDCASTS AND FORECASTS}

The model outputs from the global US Navy hindcast experiment from November 2003 to present are available through the HYCOM consortium Web page, http://www.hycom.org. The HYCOM data distribution team developed and implemented a comprehensive data management and distribution strategy that allowed easy and efficient access to the global HYCOM-based ocean prediction system output to (a) coastal and regional modeling groups, (b) the wider oceanographic and scientific community, including climate and ecosystem researchers, and (c) the general public. The outreach system consists of a Web server that acts as a gateway to backend data management, distribution, and visualization applications (http://www.hycom.org/ dataserver). These applications enable end users to obtain a broad range of services such as browsing of, for example, data sets, GIF images, NetCDF files, and FTP requests of data. The 100 terabytes HYCOM Data Sharing System is built upon two existing software components: OPeNDAP (see article by Cornillon et al., this issue) and the Live Access Server 

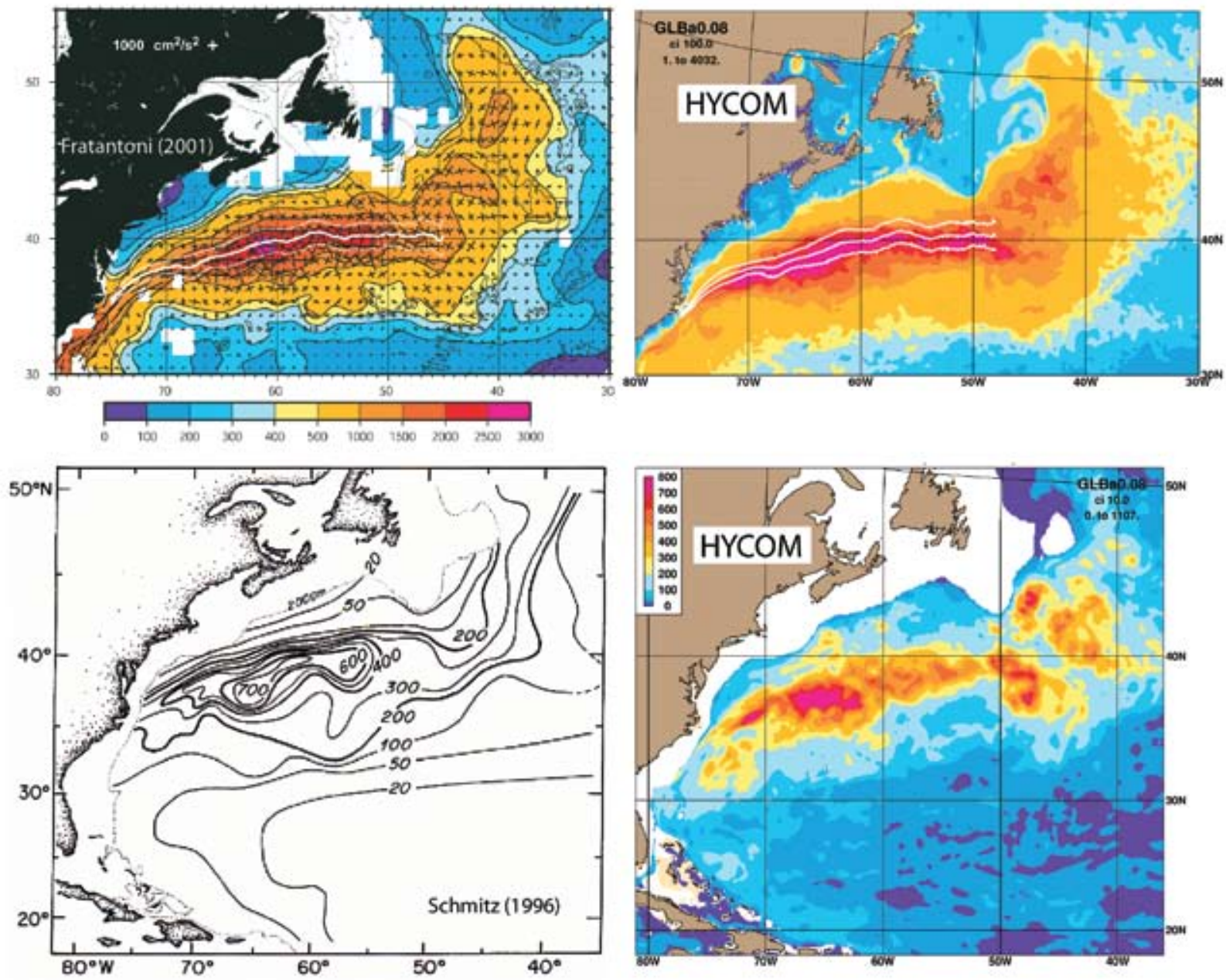

Figure 3. Surface (top panels) and $700 \mathrm{~m}$ (lower panels) eddy kinetic energy from observations (left panels) and HYCOM (over the period 2004-2006; right panels). The observed surface eddy kinetic energy (upper left panel) is from Fratantoni (2001) and the 700-m eddy kinetic energy (lower left panel) is from Schmitz (1996). The units are in $\mathrm{cm}^{2} \mathrm{~s}^{-2}$. The Gulf Stream north wall position \pm 1 standard deviation is overlaid on the top panels.

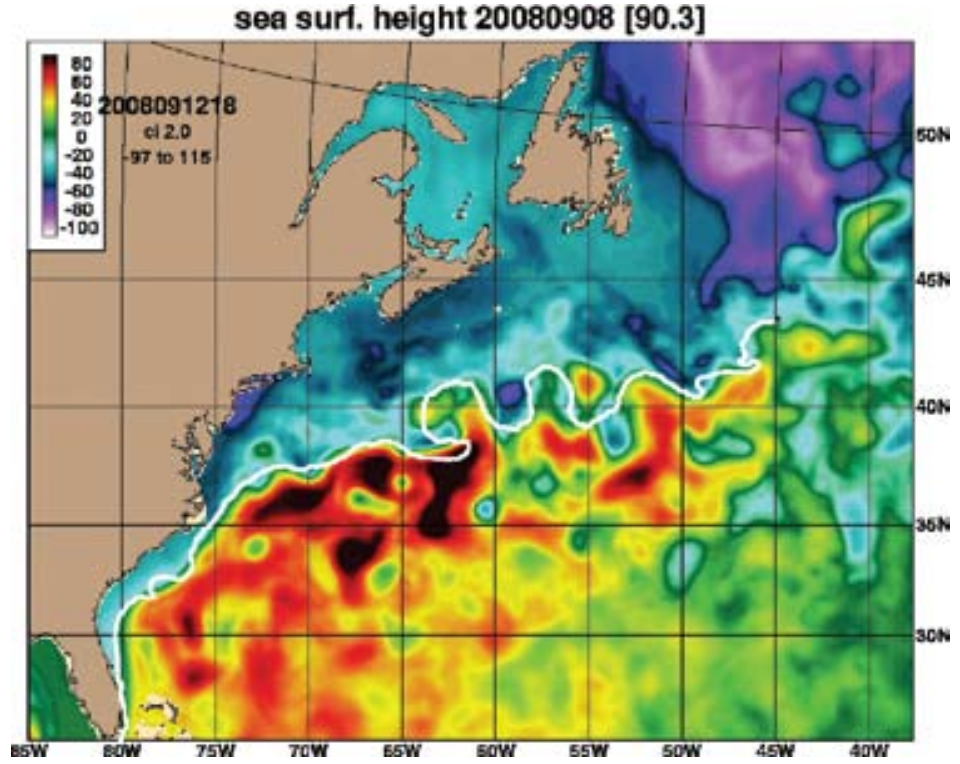

Figure 4. Modeled analysis of the sea surface height field on September 8, 2008. The white line represents the independent frontal analysis of sea surface temperature observations performed by the Naval Oceanographic Office. 


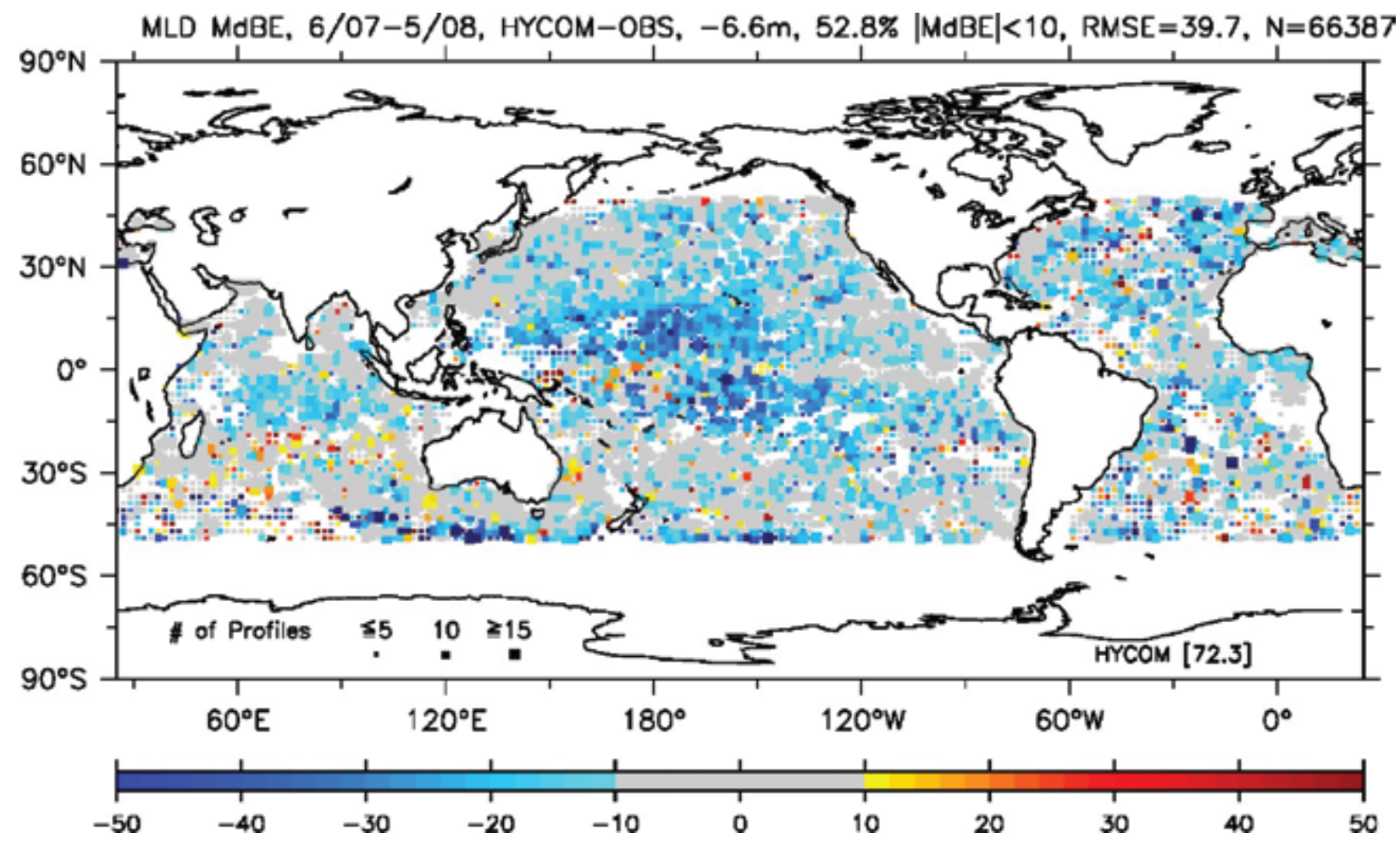

Figure 5. Median bias error (in $\mathrm{m}$ ) of mixed layer depth (MLD) calculated from simulated and approximately 66,000 unassimilated observed profiles over the period June 2007-May 2008. Blue (red) indicates a simulated MLD shallower (deeper) than observed; $53 \%$ of the simulated MLDs are within $10 \mathrm{~m}$ of the observations, and these are represented as gray. The basinwide median bias error is $-6.6 \mathrm{~m}$ and the RMS error is $40 \mathrm{~m}$.

(LAS; http://ferret.pmel.noaa.gov/LAS/). These tools and their data distribution methods are described below. In the current setup, the OPeNDAP component provides the middleware necessary to access distributed data, while LAS functions as a user interface and a product server. The abstraction offered by the OPeNDAP server also makes it possible to define a virtual data set that LAS will act upon, rather than physical files. An OPeNDAP "aggregation server" uses this approach to append model time steps from many separate files into virtual data sets. The HYCOM Data Service has been in operation for the last four years and has seen a steady increase in the user base. In the last year, the service received approximately 20,000 hits per month. In addition to the numerous requests from educational institutions and researchers, this service has been providing nearreal-time data products to several private companies in France, the Netherlands, Portugal, and the United States.

\section{BOUNDARY CONDITIONS FOR REGIONAL AND COASTAL MODELS NESTED IN HYCOM}

An important attribute of the data assimilative HYCOM system is its capability to provide boundary conditions to even higher-resolution regional and coastal models. The current horizontal and vertical resolution of the global forecasting system marginally resolves the coastal ocean $(7 \mathrm{~km}$ at mid latitudes, with up to 15 terrain-following coordinates over the shelf), but it is an excellent starting point for even higher-resolution coastal ocean prediction efforts. Several partners within the HYCOM consortium evaluated the boundary conditions and demonstrated the value added by the global and basin HYCOM data assimilative system output for coastal ocean prediction models. The inner nested models may or may not be HYCOM (i.e., the nesting procedure can handle any vertical grid choice). Outer model fields are interpolated to the horizontal and vertical grid of the nested model throughout the entire time interval of the nested model simulation at a time interval specified by the user, typically once per day. The nested model is initialized from the first archive file and the entire set of archives provides boundary conditions during the nested run, insuring consistency between initial and 


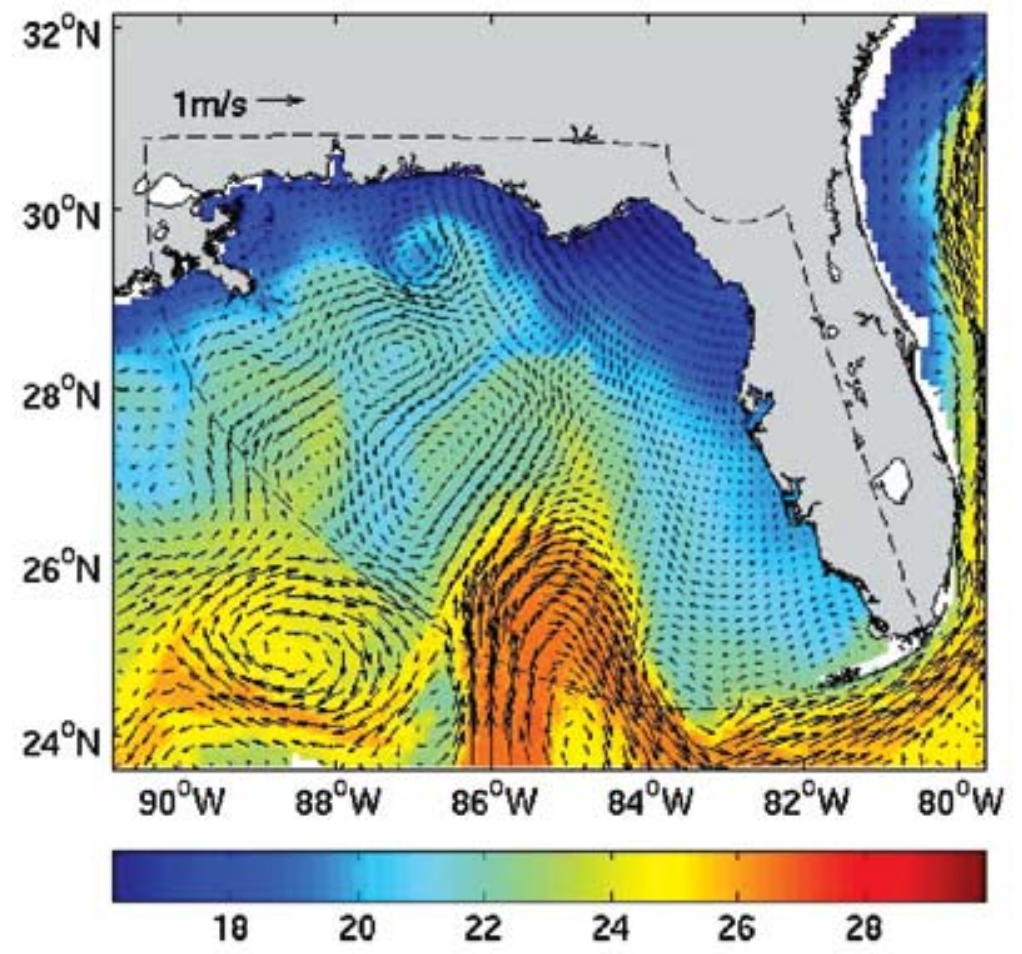

Figure 6. Sea surface temperature $\left({ }^{\circ} \mathrm{C}\right)$ and surface velocity fields from the Regional Ocean Modeling System (ROMS) West Florida Shelf domain (inside the dashed lines) and the HYCOM ocean prediction system (outside the dashed lines).
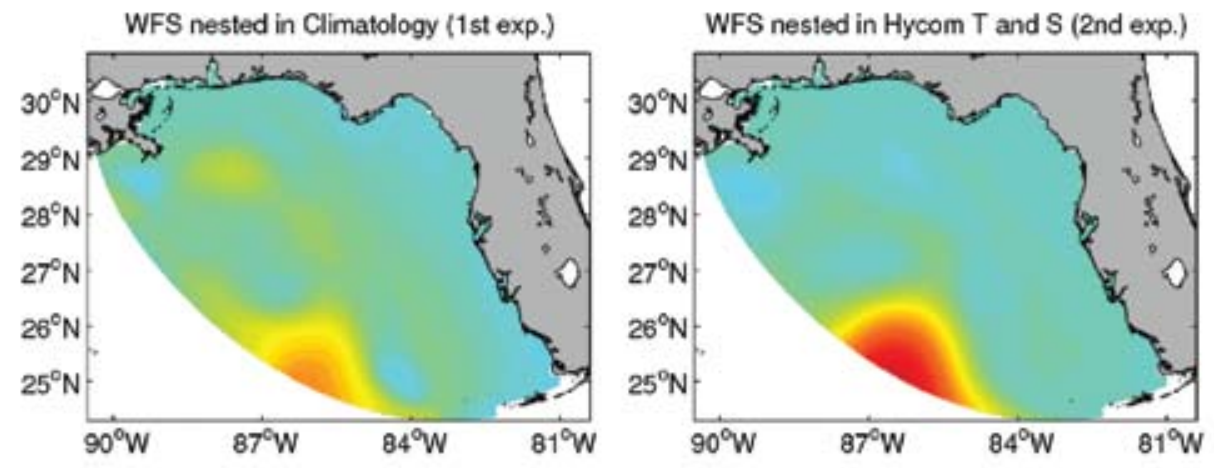

WFS fully nested in Hycom (3rd exp.)

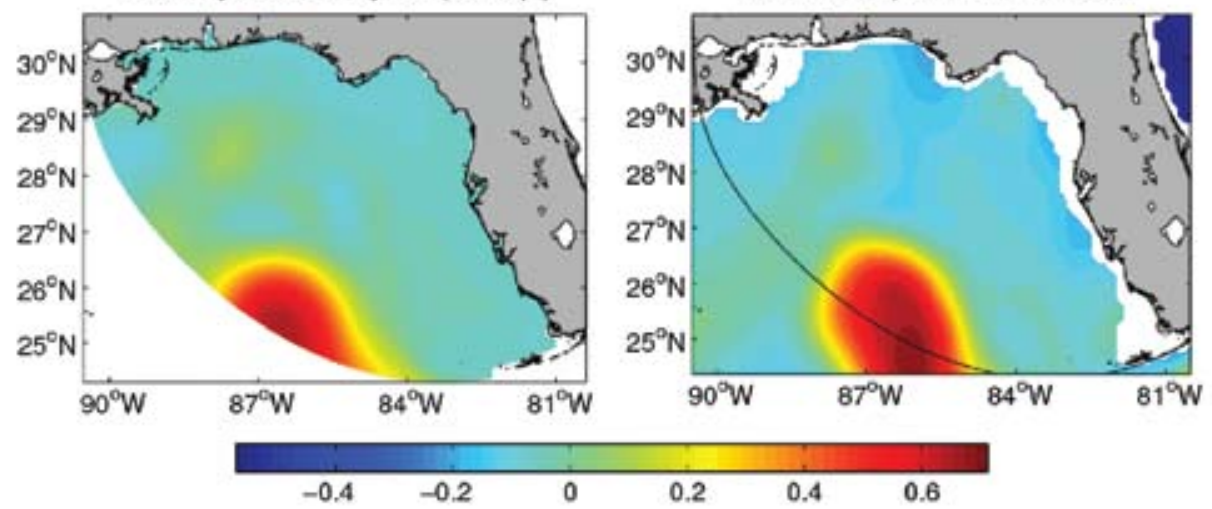

Figure 7. Mean sea surface height (in m) on April 2004 from the model (first three panels) and observations (lower right panel). WFS = West Florida Shelf. boundary conditions. This procedure has proven to be very robust.

We now describe examples that illustrate applications that benefited from the successful partnership between coastal ocean modelers and ocean prediction system developers. The main goal of the first coastal application was to assess the impact of open boundary conditions from the HYCOM ocean prediction system on the dynamics and accuracy of a regional West Florida Shelf (WFS) model (an effort led by Robert Weisberg at the University of South Florida). The Gulf of Mexico Loop Current is the main large-scale ocean feature in the WFS domain as illustrated by Figure 6, which shows an example of the SST and surface velocity fields from the West Florida Shelf domain embedded in the US Navy HYCOM ocean prediction system (Barth et al., 2008). The ocean model consists of the Regional Ocean Modeling System (ROMS) (Shchepetkin and McWilliams, 2005), and a comparison of three simulations in April 2004 is displayed in Figure 7: WFS ROMS nested in climatological temperature (T) and salinity (S) fields, WFS ROMS nested in HYCOM $\mathrm{T}$ and $\mathrm{S}$, and WFS ROMS fully nested in HYCOM. April 2004 was chosen because the Loop Current was very stable during this month (i.e., there was no eddy shedding and the Loop Current trajectory was stable and close to the climatology). A priori, the model forced with climatology should be able to reproduce the deep-ocean currents reasonably well in this situation. In the model run with climatological $\mathrm{T}$ and $\mathrm{S}$ boundary conditions, the Loop Current is too weak. With an SSH maximum of $0.3 \mathrm{~m}$ (upper left panel of Figure 7), the SSH is significantly lower than the maximum 
derived from altimetry $(0.7 \mathrm{~m}$; lower right panel of Figure 7). By using HYCOM $T$ and $S$ (upper right panel of Figure 7), the model is able to represent the Loop Current more realistically. In particular, the maximum SSH $(0.6 \mathrm{~m})$ is closer to the altimetry, but is still too low. By also using HYCOM velocity and surface elevation (lower left panel of Figure 7), the Loop Current strength (maximum SSH of .66 m) comes closest to the observations. This result indicates that the density field alone is not sufficient to completely represent the Loop Current transport. The model results from the three nesting configurations were compared with a series of moorings located on the West Florida Shelf (not shown). The model forced with climatology is too cold during summer and has the highest RMS error of all three model experiments. During summer, the model experiment forced with climatology develops an unrealistic southward coastal current. The best temperature time series is obtained with the WFS ROMS fully nested in HYCOM, which shows a more realistic current variability. The WFS ROMS model nested in HYCOM is now run on a daily basis and the full model results can be accessed and visualized at http://ocgmod1.marine.usf.edu/WFS/.

The second coastal application consists of a coupled biophysical modeling system for the South Atlantic Bight and the Gulf of Mexico. This effort is led by Ruoying He from North Carolina State University. The regional ocean model (Figure 8) consists of ROMS and is nested within the HYCOM ocean prediction system; it has $5-\mathrm{km}$ grid spacing and 36 terrainfollowing layers in the vertical. There is no ocean data assimilation, but the

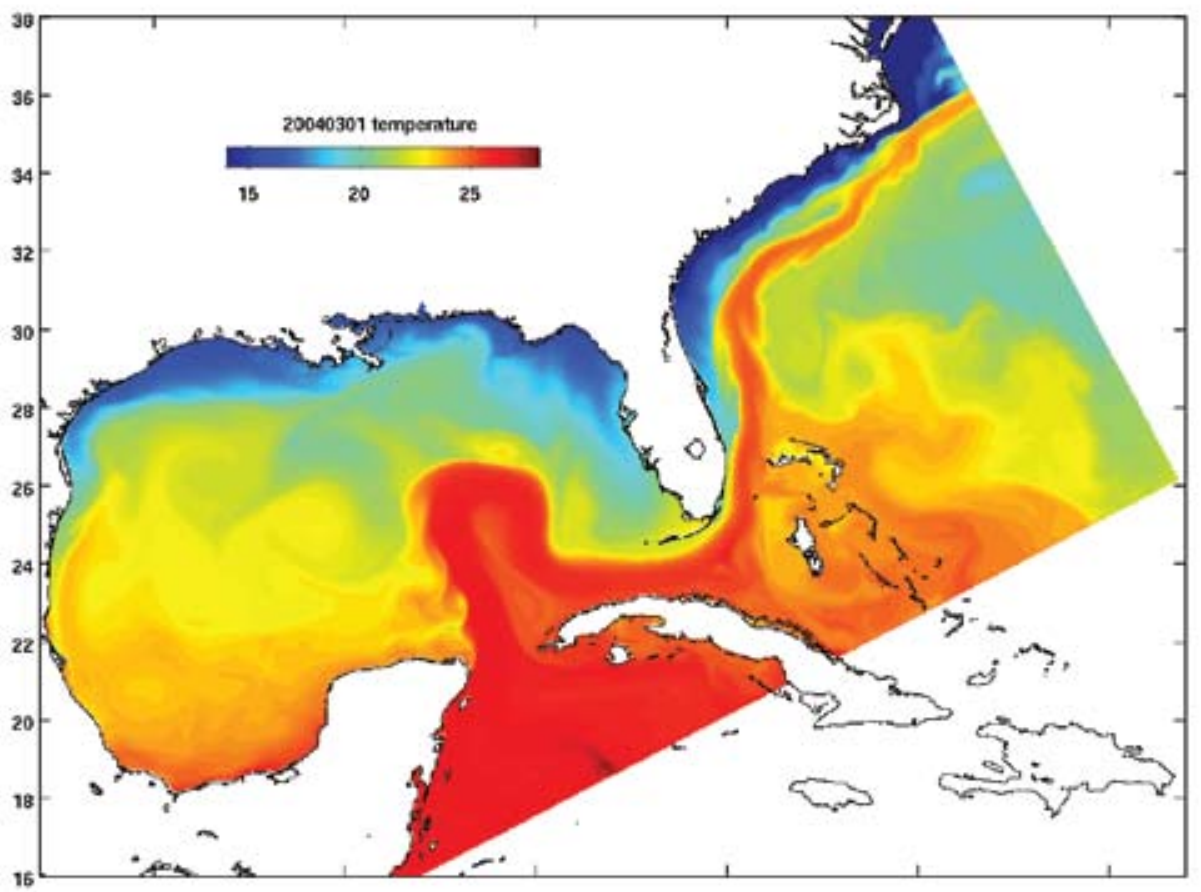

Figure 8. Sea surface temperature on March 1, 2004, for the regional 5-km ROMS domain nested within the HYCOM ocean prediction system. There is no data assimilation, but the interior $\mathrm{T}$ and $\mathrm{S}$ are relaxed to HYCOM temperature and salinity with a relaxation time of 30 days.

interior $\mathrm{T}$ and $\mathrm{S}$ are relaxed to HYCOM temperature and salinity with a 30-day relaxation time scale. This system allowed for the generation of fields of biological variables from 2004 to present using the coupled model hindcasts; Figure 9 shows an example of the modeled phytoplankton distribution for August 27, 2005. The ocean model results were validated using independent observations; Figure 10 gives an example for the University of South Florida's WFS station C19 near the Florida Keys when hurricane Katrina crossed South Florida in late August 2005.

\section{IMPACT}

In summary, 25 institutions (nine from academia, nine from government, and seven from the private sector) and approximately 60 scientists worked successfully as a team to provide an operational product that is useful not only for Navy and NOAA applications but also for in-depth scientific research and commercial applications. This effort would have not been possible without NOPP sponsorship. A measure of success is provided by the interest generated outside the partnership. For example, Kelly et al. (2007) evaluated the performance of a non-data-assimilative Pacific Ocean HYCOM in a region containing the Kuroshio Extension. They found that the HYCOM upper ocean heat budget is similar to a diagnostic heat budget inferred from observations in that the dominant contribution is from lateral fluxes, but that the advection fluctuations are much larger in the model. Commercially, HYCOM nowcasts and forecasts are often used by 


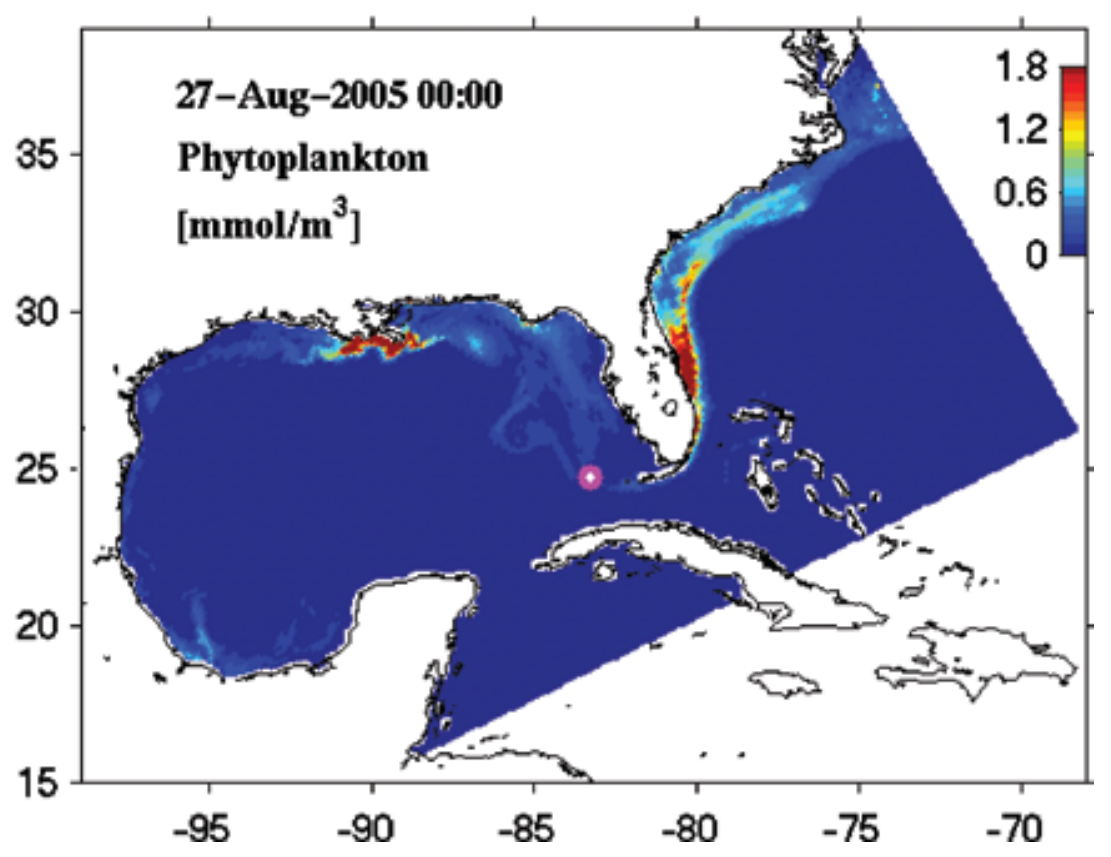

Figure 9. Modeled phytoplankton distribution $\left(\mathrm{mmol} \mathrm{m}^{-3}\right)$ on August 27,2005 . The pink dot is the location of Hurricane Katrina.
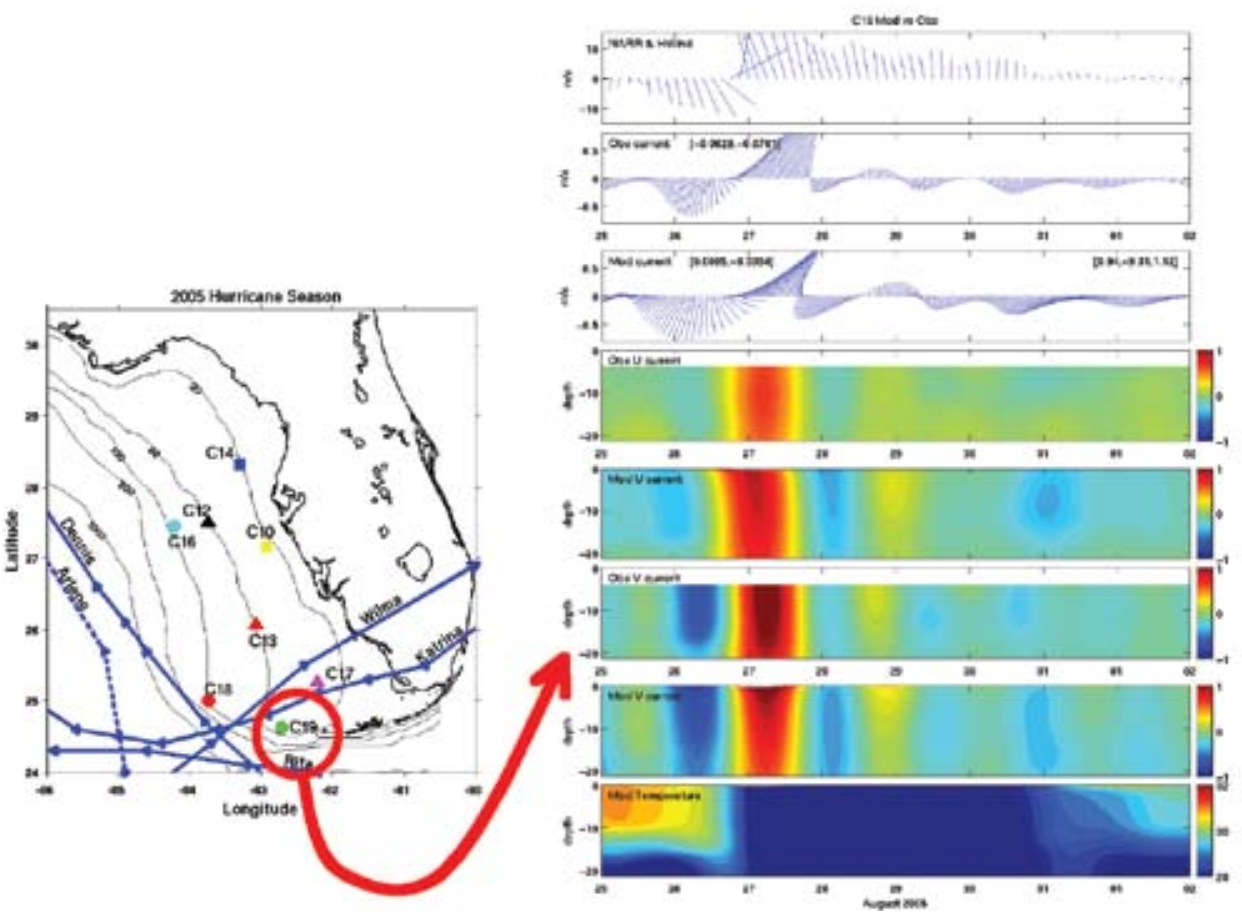

Figure 10. Modeled velocity fields versus observations at the University of South Florida's West Florida Shelf station C19 during the passage of Hurricane Katrina in late August 2005. The modeled temperature (lower panel) and observed surface winds (upper panel) are also displayed. private companies to provide ocean state information that is critically important to the cruising, shipping, fishing and workboat fleets. For example, detailed surface current information derived from HYCOM is summarized by OCENS (Ocean and Coastal ENviromental Sensing, http://www.ocens.com) for their customers who continually provide positive feedback on their accuracy.

\section{OUTLOOK}

The long-term goals of the HYCOM consortium for the global domain are to (a) add 3-D and 4-D variational data assimilation, (b) increase the horizontal resolution of the global domain to $1 / 25^{\circ}$, (c) implement two-way nesting, (d) implement zero depth coastlines with wetting and drying, and (e) include tides. The scientific goals include, but are not be limited to: (a) evaluation of the internal tides representation in support of field programs, (b) evaluation of the global model's ability to provide boundary conditions to very high resolution coastal models, (c) interaction of the open ocean with ice, (d) shelf-deep ocean interactions, (e) upper-ocean physics including mixed layer/sonic depth representation, and (f) mixing processes. Other research activities will focus on coupled ocean-wave-atmosphere prediction; bio-geo-chemical-optical and tracer/contaminant prediction; ecosystem analysis and prediction; and Earth system prediction (i.e., coupled atmosphere-ocean-ice-land).

\section{ACKNOWLEDGEMENTS}

This work was sponsored by the National Oceanographic Partnership Program (NOPP) and the Office of Naval Research (ONR). It was also supported 
in part by grants of computer time from the Defense Department High Performance Computing Modernization Program at the Naval Oceanographic Office, the Engineer Research and Development Center, and the Army Research Laboratory Major Shared Resource Centers. We would like to acknowledge the participation of the following partners:

ACADEMIA: Florida State University

Center for Ocean-Atmospheric

Prediction Studies; University of

Miami Rosenstiel School of Marine

and Atmospheric Science; Woods

Hole Oceanographic Institution; University of North Carolina at Chapel Hill; North Carolina State University; Rutgers University; University of South Florida; Laboratoire des Ecoulements Géophysiques et Industriels, Saint Martin d'Hères, France; Nansen Environmental and Remote Sensing Center, University of Bergen, Norway. GOVERNMENT: Naval Research Laboratory/Stennis Space Center and Monterey; NOAA/National Centers for Atmospheric Prediction/Marine Modeling and Analysis Branch; NOAA National Ocean Service; NOAA Atlantic Oceanographic and Meteorological Laboratory; NOAA Pacific Marine Environmental Laboratory; NOAA/ National Weather Service/Ocean Prediction Center; NASA Goddard Institute for Space Studies; Service Hydrographique et Océanographique de la Marine, Brest, France.

INDUSTRY: Planning Systems Inc.;

The Open Source Project for a Network

Data Access Protocol; Horizon Marine

Inc.; Roffer's Ocean Fishing Forecasting

Service Inc.; Shell Oil Company;

ExxonMobil Corp. 四

\section{REFERENCES}

Barth, A., A. Alvera-Azcárate, and R.H. Weisberg. 2008. Benefit of nesting a regional model into a large-scale ocean model instead of climatology: Application to the West Florida Shelf. Continental Shelf Research 28:561-573.

Bleck, R. 2002. An oceanic general circulation model framed in hybrid isopycnic-Cartesian coordinates. Ocean Modelling 4:55-88.

Bleck, R., and E.P. Chassignet. 1994. Simulating the oceanic circulation with isopycnic-coordinate models. Pp. 17-39 in: The Oceans: PhysicalChemical Dynamics and Human Impact. S.K. Majumdar, E.W. Miller, G.S. Forbes, R.F. Schmalz, and A.A. Panah, eds, The Pennsylvania Academy of Science.

Bleck, R., C. Rooth, D. Hu, and L.T. Smith. 1992. Salinity-driven transients in a wind- and thermohaline-forced isopycnic coordinate model of the North Atlantic. Journal of Physical Oceanography 22:1,486-1,505.

Carnes, M.R., D.N. Fox, R.C. Rhodes, and O.M. Smedstad. 1996. Data assimilation in a North Pacific Ocean monitoring and prediction system. Pp. 319-345 in Modern Approaches to Data Assimilation in Ocean Modeling. P. MalanotteRizzoli, ed., Elsevier, New York.

Chassignet, E.P., and Z.D. Garraffo. 2001. Viscosity parameterization and the Gulf Stream separation. Pp. 37-41 in From Stirring to Mixing in a Stratified Ocean. P. Muller and D. Henderson, eds., Proceedings 'Aha Huliko'a Hawaiian Winter Workshop. University of Hawaii, January 15-19, 2001.

Chassignet, E.P., and J. Verron, eds. 2006. Ocean Weather Forecasting: An Integrated View of Oceanography. Springer, 577 pp.

Chassignet, E.P., H.E. Hurlburt, O.M. Smedstad, G.R. Halliwell, P.J. Hogan, A.J. Wallcraft, R. Baraille, and R. Bleck. 2007. The HYCOM (HYbrid Coordinate Ocean Model) data assimilative system. Journal of Marine Systems 65:60-83.

Chassignet, E.P., H.E. Hurlburt, O.M. Smedstad, G.R. Halliwell, A.J. Wallcraft, E.J. Metzger, B.O. Blanton, C. Lozano, D.B. Rao, P.J. Hogan, and A. Srinivasan. 2006. Generalized vertical coordinates for eddy-resolving global and coastal ocean forecasts. Oceanography 19(1):118-129. Available online at: http://www.tos.org/oceanography/issues/ issue_archive/19_1.html (accessed April 9, 2009).

Chassignet, E.P., L.T. Smith, G.R. Halliwell, and R. Bleck. 2003. North Atlantic simulation with the HYbrid Coordinate Ocean Model (HYCOM): Impact of the vertical coordinate choice, reference density, and thermobaricity. Journal of Physical Oceanography 33:2,504-2,526.

Cooper, M., and K. Haines. 1996. Altimetric assimilation with water property conservation. Journal of Geophysical Research 101:1,059-1,078.

Cummings, J.A. 2005. Operational multivariate ocean data assimilation. Quarterly Journal of the Royal Meteorological Society 131:3,583-3,604.
Fox, D.N., W.J. Teague, C.N. Barron, M.R. Carnes, and C.M. Lee. 2002. The Modular Ocean Data Analysis System (MODAS). Journal of Atmospheric and Oceanic Technology 19:240-252.

Fratantoni, D.M. 2001. North Atlantic surface circulation during the 1990's observed with satellitetracked drifters. Journal of Geophysical Research 106:22,067-22,093.

Griffies, S.M., C. Böning, F.O. Bryan, E.P. Chassignet, R. Gerdes, H. Hasumi, A. Hirst, A.-M. Treguier, and D. Webb. 2000. Developments in ocean climate modelling. Ocean Modelling 2:123-192.

Halliwell, G., 2004. Evaluation of vertical coordinate and vertical mixing algorithms in the HYbrid Coordinate Ocean Model (HYCOM). Ocean Modelling 7:285-322.

Hurlburt, H.E., and P.J. Hogan. 2000. Impact of $1 / 8^{\circ}$ to $1 / 64^{\circ}$ resolution on Gulf Stream model-data comparisons in basin-scale subtropical Atlantic Ocean models. Dynamics of Atmospheres and Oceans 32:283-329.

Hurlburt, H.E., E.P. Chassignet, J.A. Cummings, A.B. Kara, E.J. Metzger, J.F. Shriver, O.M. Smedstad, A.J. Wallcraft, and C.N. Barron. 2008. Eddy-resolving global ocean prediction. Pp. 353-381 in Ocean Modeling in an Eddying Regime. M. Hecht and H. Hasumi, eds, Geophysical Monograph 177, American Geophysical Union, Washington, DC.

Kelly, K., L. Thompson, W. Cheng, and E.J. Metzger. 2007. Evaluation of HYCOM in the Kuroshio Extension region using new metrics. Journal of Geophysical Research 112, C01004, doi:10.1029/2006JC003614.

Maltrud, M.E., and J.L. McClean. 2005. An eddy resolving global $1 / 10^{\circ}$ ocean simulation. Ocean Modelling 8:31-54.

Maximenko, N.A., and P.P. Niiler. 2005. Hybrid decade-mean sea level with mesoscale resolution. Pp. 55-59 in Recent Advances in Marine Science and Technology. N. Saxena, ed., PACON International, Honolulu.

Shchepetkin, A.F., and J.C. McWilliams. 2005. The Regional Ocean Modeling System (ROMS): A split-explicit, free-surface, topography-following coordinates ocean model. Ocean Modelling 9:347-404.

Smith, R.D., M.E. Maltrud, F.O. Bryan, and M.W. Hecht, 2000. Numerical simulations of the North Atlantic Ocean at $1 / 10^{\circ}$. Journal of Physical Oceanography 30:1,532-1,561.

Schmitz, W.J. 1996. On the World Ocean Circulation. Vol. 1: Some global features/North Atlantic circulation. Woods Hole Oceanographic Institution Technical Report WHOI-96-03, 141 pp. 